\title{
Study of the parameters of spontaneous fire seats in coal pit rock dumps
}

\author{
Sergey Protasov ${ }^{1,2^{*}}$, Evgeny Seregin ${ }^{1,2}$, Vyacheslav Portola $^{2}$, Alena Bobrovnikova ${ }^{2}$, and \\ Marina Gorbacheva ${ }^{2}$ \\ ${ }^{1}$ Novation firm «KUZBASS-NIIOGR», 650054 Kemerovo, 3 Pionersky blvd., the Russian \\ Federation \\ ${ }^{2}$ T.F. Gorbachev Kuzbass State Technical University, 650000 Kemerovo, 28 Vesennyaya st., the \\ Russian Federation
}

\begin{abstract}
The presence of coal and coal-bearing rocks in waste rock dumps of open-pit coal mines contributes to the occurrence of spontaneous combustions that negatively affect the environment and people. Measurements of the temperature and the content of hazardous gases in the temperature anomaly that arose in the waste rock dump of the open-pit coal mine were made to assess the parameters of spontaneous fire seats. In the course of the study, the efficiency of detecting spontaneous fire seats in waste rock dumps was assessed by measuring the rock temperature in the wells with a depth of $2.5 \mathrm{~m}$, drilled at a distance of $20 \mathrm{~m}$ from each other. The experiment showed the difficulty of drilling control wells in waste rock dumps and the impossibility of drilling them on the slopes of dumps, especially in spontaneous fire seats with a high rock temperature. The necessity of casing control wells with pipes makes it difficult to measure the rock temperature at different depths. It was found that there are sharp drops in the rock temperature in the heated area of the dump, which cannot be detected when the wells are located at the recommended distance. The measurements showed that in all wells the temperature increases with depth, therefore the depth of wells recommended by the regulatory documents does not allow determining the size of the heated area.
\end{abstract}

\section{Introduction}

Opencast coal mining is accompanied by the movement of huge rock masses. Such disturbance of the balance of nature leads to the emergence of dangerous and harmful factors that threaten human health and life, negatively affects the natural environment [1-3]. Waste rock dumps continue to be sources of increased dust emission as long as their surfaces are not sufficiently vegetated.

Waste rock dumps contain inert and carbonaceous rocks, as well as part of coal from the mined seams. Sometimes coal seams that are not suitable for mining are also dumped. Coal decomposition activates its ability to absorb oxygen from the air. The adsorption of oxygen

*Corresponding author: psi.rmpio@kuzstu.ru 
by coal and the subsequent chemical interaction of the combustible components with the oxidizing agent lead to the release of heat. Under favorable conditions for heat exchange with the environment, the temperature of coal-bearing rock accumulations increases and spontaneous combustion occurs.

The danger of waste rock dumps increases dramatically in the event of spontaneous fires. Rocks containing such combustible components as coal and sulfur is known to be ignitable $[4,5,6,7]$. An increase in the rock temperature caused by the occurrence of spontaneous combustion sharply increases the release into the air of hazardous gases formed during oxidative reactions. The intensity of dust emission from the rock deprived of moisture increases. Toxic products of thermal decomposition of coal get into the soil, groundwater and surface water bodies. There are known cases of explosions of burning rock dumps due to the ingress of water into hot rocks.

The danger of spontaneous fires for coal enterprises (mines, open-pit mines and processing plants) necessitates extensive studies of the conditions under which spontaneous combustion occurs [8-14]. The use of the developed methods for the prevention of spontaneous combustions has made it possible to significantly reduce the number of spontaneous fires that occurred in coal mines in recent years in Russia. The study of the features of the occurrence of spontaneous combustions in waste rock dumps of open-pit coal mines is also being carried out.

In order to reduce damage to the environment from spontaneous fires occurring in waste rock dumps, the rock temperature control is enhanced, which makes it possible to detect the processes of oxidation and spontaneous combustion of coal-bearing rocks at an early stage. According to the current regulatory documents, temperature surveys must be carried out:

- 3 times a year (May, July and September) in operated dumps that are not burning;

- 2 times a year (May and September) in operated burning dumps;

- once a year (September) in decommissioned burning dumps.

The temperature measurement points are located on the entire surface of a dump, including the slopes of a dump, every $20 \mathrm{~m}$. In this case, the rock temperature is supposed to be determined at depths of $0.5 \mathrm{~m}, 1.5 \mathrm{~m}$ and $2.5 \mathrm{~m}$ from the dump surface.

Analysis of methods for detecting and monitoring spontaneous combustion processes in waste rock dumps raises doubts about the possibility of their practical application. For example, the areas of many waste dumps are about 1 million $\mathrm{m}^{2}$ or more, and the rock volume reaches tens of millions $\mathrm{m}^{3}$, therefore, the number of control points required to measure the temperature of the rock of such a dump can be several thousand. Since the temperature of the crushed masses, especially at depths of $1.5 \mathrm{~m}$ and $2.5 \mathrm{~m}$ from the dump surface, can only be measured by drilling wells, the question arises about the economic feasibility of such operation. Drilling wells in spontaneous fire seats with a high temperature of the upper rock layer poses a particular danger. It is difficult, and often impossible, to drill control wells and take temperature measurements on the slopes of waste rock dumps.

The studies of the temperature anomalies at the test site of the burning waste rock dump were carried out to assess the efficiency of the recommended parameters of temperature survey of waste rock dumps. Drilling of the control wells and subsequent measurements were carried out at the test site of the waste rock dump, which had visible and tangible signs of spontaneous fire. There were cracks in the dump, emitting a small amount of smoke, the surface of which was covered with resins formed during the thermal decomposition of coal. The surface layer of the rock was heated, the smell of coal pyrolyzates was felt in the air.

The test site of the waste rock dump had dimensions of $20 \times 20 \mathrm{~m}$. In order to study in detail the features of the temperature distribution in the heated area of the dump, some of 
the wells were drilled at $2.5 \mathrm{~m}, 5 \mathrm{~m}$ and $10 \mathrm{~m}$ intervals. The rock temperature was measured at depths of $0.5 \mathrm{~m}, 1.5 \mathrm{~m}$ and $2.5 \mathrm{~m}$.

A number of problems arose while drilling the control wells in the waste rock dump. So, at several planned points, drilling had to be stopped due to high rock temperatures and the risk of the drilling rig ignition. The experiment also showed that temperature measurement at a given depth of $2.5 \mathrm{~m}$ is possible only in the wells cased with pipes throughout their length. Without casing, the wells were usually backfilled with loose rock when the drilling tool was pulled back. A total of 15 wells were drilled in the test site, which were cased with metal pipes with an inner diameter of $125 \mathrm{~mm}$. The location of the wells and the distance between them are shown in Fig. 1. To measure the rock temperature at depths of $0.5 \mathrm{~m}$ and $1.5 \mathrm{~m}$ from the surface of the dump, $4 \times 15 \mathrm{~cm}$ windows were cut in the casing pipes at a given depth.

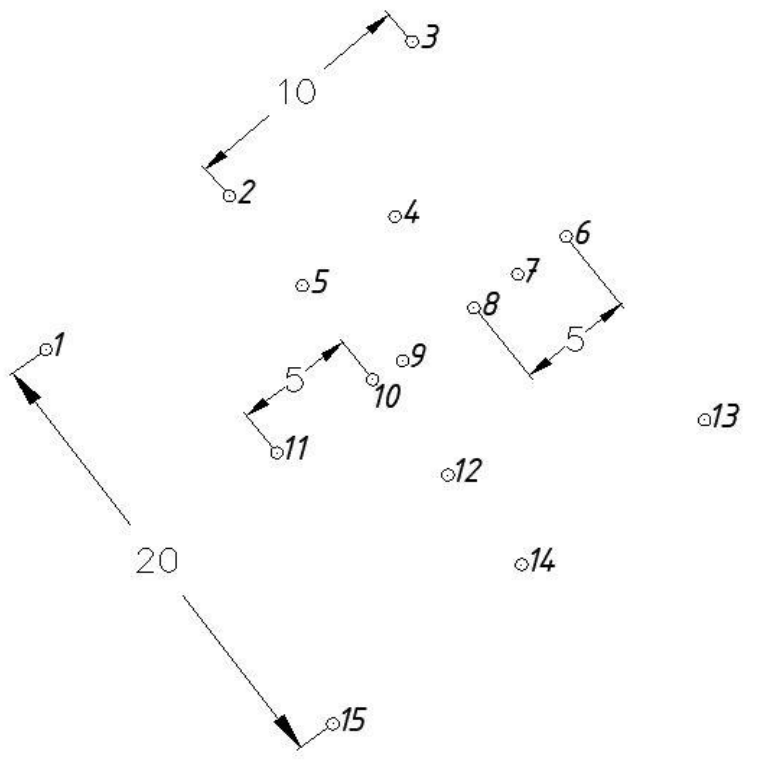

Fig. 1. The layout of the wells for measuring the rock temperature at different depths

It was found that casing of wells with metal pipes significantly complicated the rock temperature measurements. Coal and its solid combustion products have thermal insulation properties and have a thermal conductivity coefficient of $0.2-0.3 \mathrm{~W} /(\mathrm{m} \cdot \mathrm{K})$. The thermal conductivity coefficient of steel is hundreds of times higher, exceeding $50 \mathrm{~W} /(\mathrm{m} \cdot \mathrm{K})$, which leads to heating of the casing along the entire length. As a result, the casing temperature can be significantly different from the coal-bearing rock temperature. In addition, the transfer of heat by the casing leads to the transfer of heat from the source and the outbreaks of new spontaneous combustions with a high temperature of the upper rock layer.

The dump rock temperature was measured in the wells at depths of $0.5 \mathrm{~m}, 1.5 \mathrm{~m}$ and 2.5 $\mathrm{m}$, as well as on the surface of the dump next to the well. For this, a contact thermometer with $1.0 \mathrm{~m}, 1.5 \mathrm{~m}$ and $2.5 \mathrm{~m}$ long probes was used, as well as a CEM DT-9860S pyrometer with a probe sunk down to a depth of $3.5 \mathrm{~m}$. The need to hit the probe into the windows cut in the pipe to provide its contact with the rock significantly slowed down the temperature survey. 


\section{Research Results}

A full set of measurements of the dump rock temperature in the wells of the test site at all studied depths was carried out in early September. The air temperature during measurement was $16.0^{\circ} \mathrm{C}$. The results of temperature measurements in the wells at a depth of $2.5 \mathrm{~m}$ are shown in Fig. 2. Numbering of the wells in Fig. 2 corresponds to that in Fig. 1.

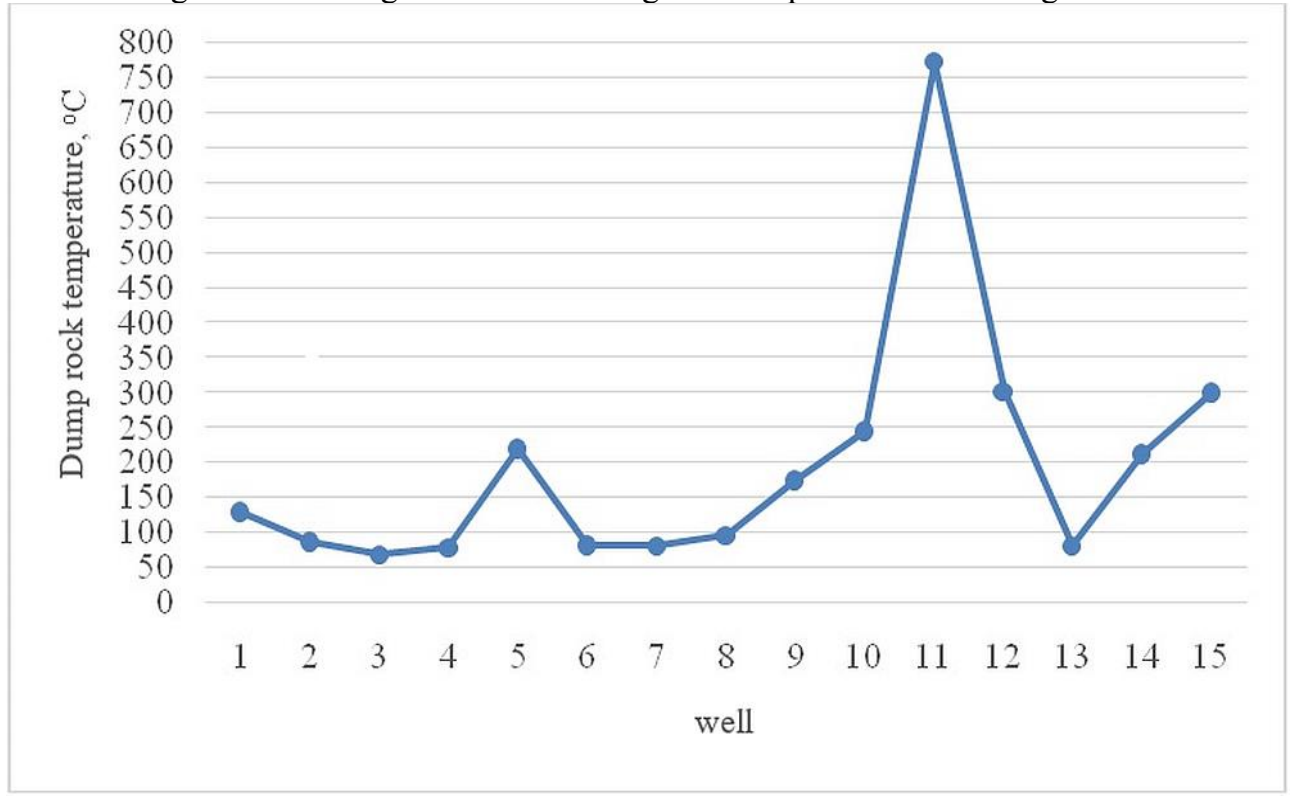

Fig. 2. Change in the rock temperature in the wells at a depth of $2.5 \mathrm{~m}$

Analyzing the obtained results of measurements shown in Fig. 2, it can be concluded that the rock temperature in spontaneous fire seat can change significantly over a short distance. Thus, the rock temperature spread in an area of $20 \times 20 \mathrm{~m}$ at a depth of $2.5 \mathrm{~m}$ ranged from 69 to $773^{\circ} \mathrm{C}$. The epicenter of the temperature anomaly is in the well No. 11 . Between the wells No. 10 and No. 11, located at a distance of $5 \mathrm{~m}$ from each other, the temperature difference reached 521 degrees. The reason for such fluctuations in the rock temperature may be a significant change in the content of coal in the waste rock, leading to fluctuations in a wide range of oxygen sorption activity of coal-bearing rock and the amount of heat released.

The uneven heating of the waste rock dump may also be caused by the differences in the influx of air to the combustible components. Thus, the presence of cracks greatly simplifies the air flow and, with a high content of coal in the rock, contributes to a rapid increase in the temperature. The volume of oxygen entering into the depth of the dump will also depend on the rock permeability and the surface relief. The insulating properties of coal and combustion products also contribute to sudden temperature changes.

Taking into account significant fluctuations in the rock temperature at small distances, the recommended distance between the temperature measurement points of $20 \mathrm{~m}$ can give a distorted idea of the parameters of spontaneous fire seats in the dump. The spontaneous fire seats, the diameters of which were 1-10 m, were also observed in the studied dump. With the recommended distances between the measurement points, such seats of fire may not be found.

It also follows from the measurement results that the rock temperature increases with the depth of wells. Figure 3 shows the change in the rock temperature at different depths in the wells No. 1 , No. 8 , No. 10, No. 11 and No. 15. The obtained patterns indicate that the 
maximum temperatures of the dump rocks in this area are at a depth exceeding $2.5 \mathrm{~m}$. Therefore, the specified depth of measurements, limited to $2.5 \mathrm{~m}$, does not allow determining the real size of the rock layer heated into the depth of the dump and assessing the dimensions of spontaneous fire seats. Accordingly, when elaborating measures to extinguish a spontaneous fire, it is impossible to calculate the amount of refrigerant required to cool the heated rock mass.
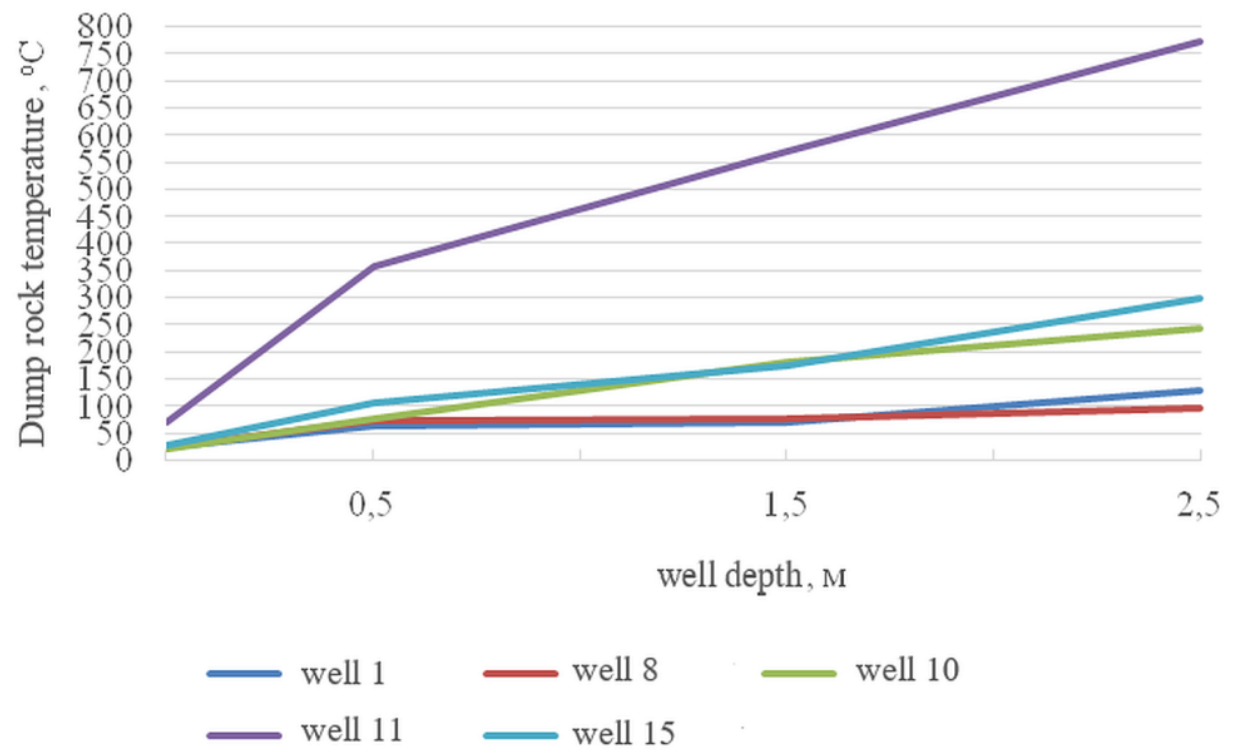

Fig. 3. Change in the rock temperature along the depth of wells

Considering the duration, complexity and high cost of drilling control wells in waste rock dumps to a depth of $2.5 \mathrm{~m}$, as well as insufficient information content of measurements, it is advisable to use less costly methods for detecting spontaneous fire seats in waste rock dumps. So, the simplest one is to measure the temperature of the surface layer of a dump. To do this, thermal imagers with high resolution in the infrared range can be uses.

To assess the relationship between the temperature of the surface layer and the rock in the depth of the dump, the results of temperature measurements in the wells at a depth of 1.5 and $0.5 \mathrm{~m}$, as well as in the surface rock layer, are shown in Fig. 4. 


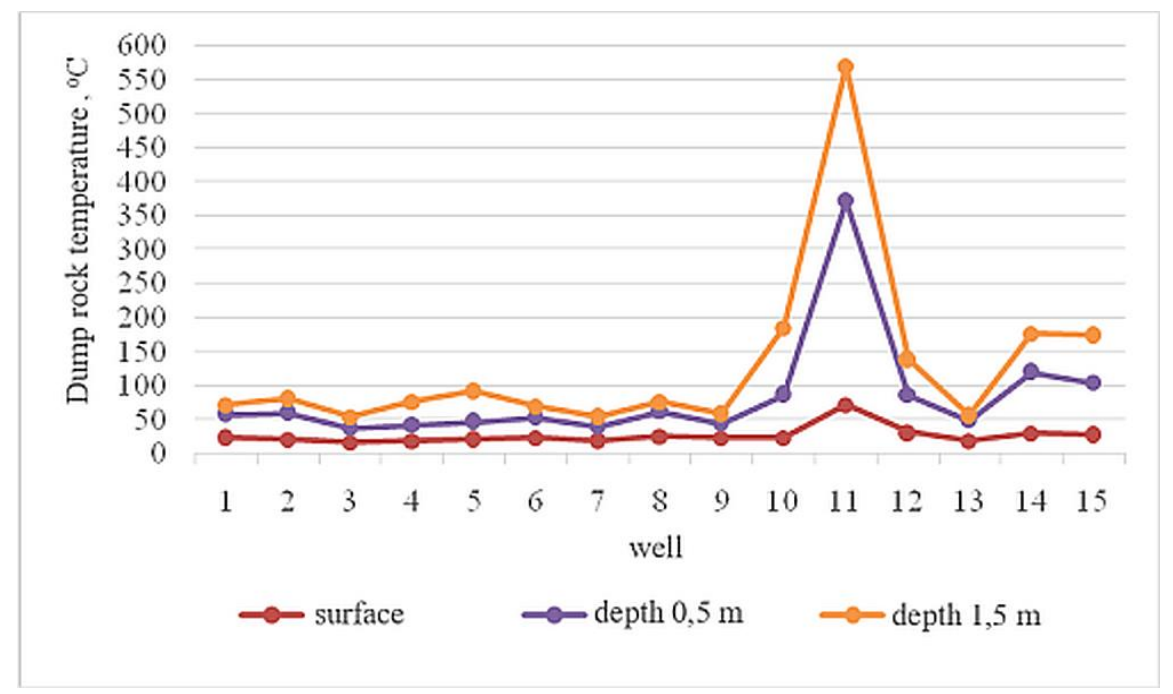

Fig. 4. Change in the rock temperature on the surface and in the wells at a depth of $0.5 \mathrm{~m}$ and $1.5 \mathrm{~m}$

Analyzing the results of these measurements, it can be concluded that the surface temperature of the test area with the spontaneous fire seat always differs from the air temperature. The difference between the temperature of the surface layer and the air ranged from 3 to 55 degrees. Moreover, the temperature of the surface layer changes in proportion to the rock temperature in the depth of the dump, which makes it possible to use remote temperature measuring devices (thermal imagers and pyrometers) to detect spontaneous fires in waste rock dumps. The results of such a survey make it possible to build isotherms and identify the epicenters of spontaneous combustions in the dump.

The calculation showed that the average rock temperature within the test site area was $135.5^{\circ} \mathrm{C}$. The volume of the rock in an area of $400 \mathrm{~m}^{2}$ with a depth of $2.5 \mathrm{~m}$ was equal to $1000 \mathrm{~m}^{3}$. The heat content of this heated rock mass can be calculated by the formula

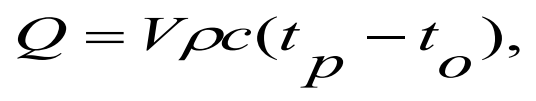

where $V$ - volume of the heated rock accumulation, $\mathrm{m}^{3} ; \rho$ - rock density, $\mathrm{kg} / \mathrm{m}^{3} ; c-$ specific heat of the coal-bearing rock, $\mathrm{kJ} /(\mathrm{kg} \mathrm{K}) ; t_{p}$ - temperature of the heated rock accumulation, $\mathrm{K} ; t_{o}$ - initial temperature of the rock accumulation, $\mathrm{K}$.

Calculation using formula (1) showed that the heat content of the rock in the study area is $260000 \mathrm{MJ}$. In the calculations, the density of the coal-bearing rock mass was equal to $1500 \mathrm{~kg} / \mathrm{m}^{3}$, and its specific heat capacity was $1.5 \mathrm{~kJ} /(\mathrm{kg} \cdot \mathrm{K})$. The average temperature of the heated rock masses reached $135.5^{\circ} \mathrm{C}$, and the initial rock temperature was $20^{\circ} \mathrm{C}$. The heat content of each $\mathrm{m}^{3}$ of the rock averaged $260 \mathrm{MJ}$.

Portable gas analyzers GasAlertMicroClip XL, GasAlertExtreme and Drager X-am 5000 were used to measure the composition of gases emitted from the spontaneous combustion areas, which allow measuring the concentrations of methane $\left(\mathrm{CH}_{4}\right)$, carbon monoxide $(\mathrm{CO})$, sulfur dioxide $\left(\mathrm{SO}_{2}\right)$ or sulfur dioxide, hydrogen sulfide $\left(\mathrm{H}_{2} \mathrm{~S}\right)$ oxygen $\left(\mathrm{O}_{2}\right)$. Gas samples were taken in the wells at a depth of $0.5 \mathrm{~m}$. Measurements showed a high concentration of carbon monoxide in the wells. The carbon monoxide content in all wells exceeded $0.2000 \%$ (the upper measurement limit of the gas analyzer). All wells contained methane, the concentration of which reached 5\%. Sulfur dioxide was present in almost all wells, but its concentration did not exceed $0.0003 \%$. The intensity of hydrogen sulfide 
emission by the rock was much higher and its concentration in some wells exceeded $0.0100 \%$. The oxygen content in the wells ranged from 4 to $20 \%$. According to the composition of the emitted gases, it can be concluded that the combustible elements of the dump rocks are carbon and sulfur.

Based on the results of the studies carried out, it can be concluded that the greatest temperature difference in the dump rock is observed between the surface layer and the rock at a depth of $0.5 \mathrm{~m}$. Considering that the rock temperature at such a depth is proportional to its temperature at a depth of $2.5 \mathrm{~m}$, the measurements taken are sufficient not only to detect spontaneous fire seats, but also to evaluate their parameters. After surface thermal imaging survey of the identified spontaneous fire seat, it is advisable to carry out contact measurement at a depth of $0.5 \mathrm{~m}$ to check the results obtained. At the same time, to determine the temperature at a depth of $0.5 \mathrm{~m}$, it is enough to use a temperature probe or drill a small diameter hole, which will significantly reduce the cost of taking a temperature survey and the duration of measurement. Then, based on the results of the survey, appropriate measures are elaborated to prevent the development of spontaneous combustion, as well as to suppress fires.

\section{Conclusions}

Based on the results obtained, the following conclusions can be drawn.

1. The recommended distance between the control points of temperature measurement, equal to $20 \mathrm{~m}$, does not allow obtaining reliable data on the state and location of spontaneous combustions in waste rock dumps due to significant horizontal temperature drops in the rocks.

2. Almost in all wells drilled in the spontaneous fire zone to a depth of $2.5 \mathrm{~m}$, an increase in the rock temperature is observed with an increase in the depth of the well. At the same time, the recommended depth of control wells, equal to $2.5 \mathrm{~m}$, does not allow determining the size of the area heated into the depth of the waste rock dump.

3. The temperature of the upper rock layer above the spontaneous fire seat exceeds the temperature of the surrounding air, therefore, remote temperature measuring devices can be used to detect spontaneous fires in waste rock dumps.

4. The temperature distribution in the upper rock layer of the burning dump follows the temperature distribution at the dump depth, but in a smoothed form. Taking into account that the greatest temperature difference was recorded at a depth of $0.5 \mathrm{~m}$, for a control assessment of the parameters of the spontaneous fire seat of a dump, it is sufficient to measure the rock temperature at a depth of $0.5 \mathrm{~m}$.

5. For early detection of spontaneous combustions of waste rock dumps, it is advisable to use thermal imaging of the dump surface using unmanned aerial vehicles.

\section{References}

1. S.S. Timofeeva, P. YanKova, S.S. Timofeev, N.Y. Lugovtsova, IOP Conference Series: Earth and Environmental Science. Current Problems and Solutions, 012057 (2019)

2. V. Portola, A. Bobrovnikova, E. Murko, The 9th Russian-Chinese Symposium. Coal in the 21st Century: Mining, Intelligent Equipment and Environmental Protection, 345 (2018)

3. M.L.S. Oliveira, K. da Boit, F. Pacheco, E.C. Teixeira, I.L. Schneider, T.J. Crissien, D.C. Pinto, R.M. Oyaga, L.F.O. Silva, Environ Res, 160, 562 (2018)

4. R. Morris, T. Atkinson, Mining Science and Technology, 7, 2, 149 (1988) 
5. M. Onifade, B. Genc, International Journal of Mining Science and Technology, 28, 993 (2018)

6. R. Payant, F. Rosenblum, J. Nesset, and J. Finch, Proceedings of the 43rd Annual Canadian Mineral Processors Conference (2011)

7. F. Rosenblum, and Nesset, J., CIMbulletin, 94, 92 (2001)

8. V.A. Portola, Journal of Mining Science, 32, 6, 536 (1996)

9. Q. Lin, S. Wang, S. Song, Y. Liang, T. Ren, Fuel Processing Technology, 159, 38 (2017)

10. W. Liu, Y. Qin, X. Yang, W. Wang, Y. Chen, Fuel, 217, 544 (2018)

11. H. Yuan, F. Restuccia, F. Richter, G. Rein, Fuel, 236, 1100 (2019)

12. Y. Liang, and S. Wang, Fire Safety Journal, 87, 49 (2017)

13. J. Wang, Y. Zhang, S. Xue, J. Wu, Y. Tang, L. Chang, Technol, 179, 60 (2018)

14. E.I. Kabanov, G.I. Korshunov, R.D. Magomet, Journal of applied science and engineering, 34, 1, 292 (2021) 